\title{
Perkaitan orientasi matlamat dan keseronokan dalam kalangan atlet hoki UPSI
}

\author{
Norsaleha Mohd Ariffin, Nabilah Yaakub \& Nelfianty Mohd Rasyid \\ Fakulti Sains Sukan dan Kejurulatihan, Universiti Pendidikan Sultan Idris, Malaysia \\ Jurnal Sains Sukan dan Pendidikan Jasmani 8(2): 35-43, Received: 1 Julai 2019, Accepted: 15 \\ Disember 2019
}

DOI: https://doi.org/10.37134/jsspj.vol8.2.4.2019

\begin{abstract}
Abstrak
Kajian ini bertujuan untuk mengkaji hubungan antara orientasi matlamat dan keseronokan dalam kalangan atlet hoki UPSI. Kajian tinjauan ini dijalankan dalam kalangan 30 orang altet yang mewakili UPSI dalam kejohanan hoki peringkat Universiti (lelaki, $\mathrm{n}=17$; perempuan, $\mathrm{n}=13$ ). Instrumen soal selidik Task and Ego Orientation Sport Questionnaire (TEOSQ) dan Physical Activity Enjoyment Scale (PACES) digunakan untuk mengukur orientasi matlamat dan tahap keseronokan. Analisis deskriptif min dan sisihan piawai; analisis inferens Ujian-t sampel tidak bersandar serta korelasi digunakan untuk mengenalpasti orientasi matlamat dan tahap keseronokan atlet serta perkaitan antara kedua-duanya. Dapatan kajian menunjukkan atlet hoki UPSI lebih berorientasikan tugasan berbanding ego dan mempunyai tahap keseronokan yang sederhana. Hasil keputusan inferens korelasi turut menunjukkan terdapat perkaitan yang signifikan $(\mathrm{p}=0.001, \mathrm{p}<0.05)$ diantara orientasi ego dengan keseronokan atlet hoki UPSI. Aspek orientasi ego secara tidak langsung memberi kesan yang positif terhadap tahap keseronokan atlet. Atlet hoki perlu diterapkan latihan kemahiran psikologi yang lebih spesifik dan memberi kesan kepada peningkatan orientasi matlamat kerana ia mempengaruhi tahap keseronokan atlet.
\end{abstract}

Kata Kunci Orientasi tugasan, orientasi ego, tahap keseronokan, atlet hoki

\section{Relationship of goal orientation and enjoyment among UPSI hockey athletes}

\begin{abstract}
The purpose of this study is to examine the relationship between goal orientation and level of enjoyment among UPSI hockey athletes. 30 athletes (male, $n=17$; female, $n=13$ ) representing UPSI Hockey teams in the university tournament participated in this survey method research. Task and Ego Orientation in Sport Questionnaire (TEOSQ) and Physical Activity Enjoyment Scale (PACES) questionnaire was used to measure goal orientation and level of athletes' enjoyment. Descriptive analysis mean and standard deviation; independent sample t-test and correlation was employed to identify the goal orientation, level of enjoyment and relationship of both variables. UPSI hockey athletes were more task-oriented than ego-oriented, and their level of enjoyment was moderate. The inference correlation showed there was a significant different $(p=0.001, p<0.05)$ between the ego orientation and the level of enjoyment of UPSI hockey athletes. In conclusion, the ego orientation indirectly gives the positive impact toward athletes' enjoyment aspect. Specific psychological skill training should be applied on hockey athletes to increase their goal orientation in intensified their level of enjoyment.
\end{abstract}

Keywords Goal orientation, ego orientation, task orientation, enjoyment, hockey athletes 


\section{PENGENALAN}

Penetapan matlamat merupakan suatu elemen yang mempengaruhi prestasi individu dalam sukan dan mempunyai hala tuju yang jelas serta garis panduan untuk merealisasikan sesuatu matlamat.Orientasi matlamat merangkumi daya usaha, faktor luaran, dan kemampuan seseorang individu yang mempunyai hubungkait terhadap kejayaan dalam sukan di peringkat kebangsaan dan antarabangsa (Sofian \& Razak, 2005). Dalam sukan berkumpulan, matlamat atlet adalah berfokus kepada orientasi tugasan seperti meningkatkan prestasi berbanding ego iaitu berasa lebih baik daripada orang lain (Lameiras, Almeida \& Garcia-Mas, 2014). Orientasi tugasan merujuk kepada penghasilan kecekapan melalui peningkatan kemahiran dan kecekapan peribadi serta penguasaan tugas (Saadan, Hooi, Ali \& Jano, 2016).

Orientasi ego pula memberi penekanan terhadap individu untuk mempamerkan diri dan membandingkan prestasinya dengan orang lain. Menurut Lochbaum, Kallinen \& Konttinen, (2017) orientasi ego berfungsi apabila atlet mempunyai keinginan untuk menunjukkan kecekapan normatif seperti mengalahkan pihak lawan, keupayaan untuk menjadi lebih cemerlang dan mempamerkan motivasi dalam bertingkah laku.

Saadan et.al (2016) telah mengkaji hubungan antara kebimbangan pertandingan dan orientasi matlamat terhadap 144 atlet junior hoki (72 lelaki;72 wanita) yang berumur antara 15 tahun hingga 18 tahun di Malaysia. Dapatan kajian menunjukkan bahawa atlet wanita mempunyai orientasi tugasan yang lebih tinggi berbanding atlet lelaki manakala, atlet lelaki mempunyai orientasi ego yang lebih tinggi berbanding atlet wanita. Menurut Sorate \& Khan (2016), persepsi individu terhadap keupayaan diri secara lazimnya menjadikan diri sendiri sebagai rujukan; minat dalam pembelajaran, pembangunan diri serta fokus dan bekerja keras dalam meningkatkan tugasan tanpa memikirkan kesan yang akan datang. Hasil kajian terhadap 50 atlet di Universiti Jimma mendapati bahawa secara keseluruhannya semua atlet mempunyai tahap orientasi ego yang sederhana. Manakala, peserta bagi kumpulan bolasepak, pingpong dan olahraga mempunyai orientasi tugasan yang lebih tinggi berbanding peserta bola keranjang dan gimnastik.

Keseronokan dalam sukan boleh didefinisikan sebagai emosi atau perasaan suka, kenikmatan dan kegembiraan individu yang mencerminkan tindak balas yang positif berdasarkan pengalaman yang beterusan individu tersebut dalam sukan (Scanlan, Carpenter, Lobel, Simons, 1993). Elemen keseronokan merupakan salah satu sebab utama atlet menyertai sukan dan ianya juga boleh menjadi penyebab utama dalam penurunan prestasi atlet jika elemen keseronokan tersebut berkurang. Clark (2005), turut menyatakan keseronokan merupakan elemen psikologi yang positif yang menjadi tunjang utama dalam motivasi dan komitmen dalam sukan. Untuk mengekalkan atau meningkatkan keseronokan dalam kalangan atlet, latihan kemahiran psikologi sukan boleh dipraktikkan (Weiss Ferrer-Caja, 2002).

Kegigihan dan usaha keras atlet dalam sukan merupakan kesan motivasi yang positif yang ditafsirkan daripada elemen keseronokan. Clark (2005) menyatakan elemen keseronokan boleh didapati daripada tiga sumber iaitu intrapersonal, situasi, dan sumber luaran. Aspek intrapersonal merangkumi persepsi atlet terhadap sukan, orientasi matlamat atlet dalam sukan, dan pengalaman mereka sepanjang penglibatan dalam sukan manakala aspek situasi ialah situasi dimana atlet menerima pengiktirafan kejayaan mereka dalam sukan (Weiss \& Ferrer-Caja, 2002). Aspek seterusnya ialah sumber lain yang penting dan memberi kesan yang positif seperti galakan daripada ibu bapa, jurulatih, dan rakan sepasukan.

Selain itu, kanak-kanak lelaki dikatakan lebih aktif dan lebih menikmati keseronokan dalam sukan berbanding kanak-kanak perempuan. Johnson, Erwin, Kipp \& Beighle (2017) dalam kajian mereka yang mengkaji persepsi pelajar mengenai perspektif motivasi pedagogi guru dalam mengendalikan latihan. Berdasarkan kajian tersebut, terdapat hubungan yang positif diantara motivasi dan keseronokan. Jaakkola, Ntoumanis, \& Liukkonen, (2016) menjalankan kajian mengenai hubungan antara keadaan iklim motivasi, matlamat pencapaian dalam pendekatan pencegahan, keupayaan atau kebolehan dan keseronokan dalam sukan. Hasil kajian mendapati bahawa keadaan iklim motivasi menekankan aspek usaha dan pembangunan peribadi untuk penambahbaikannya manakala orientasi matlamat merupakan aspek penting dalam elemen keseronokan dalam sukan. 
Perkaitan antara keseronokan dengan penglibatan dalam sukan turut dikaji oleh Michael, Scoffield, Lee, \& Fulton (2016) yang berpendapat bahawa bilangan aktiviti fizikal mempunyai perkaitan yang rapat dengan peningkatan keseronokan. Penyertaan dalam sesuatu sukan atau acara turut dikaitkan dengan tahap keseronokan atlet tidak mengira jantina dan sukan. Tambahan lagi, Schneider, Harrington, \& Tobar (2017) menyatakan bahawa atlet yang berorientasikan tugasan dikatakan lebih seronok dan lebih menikmati permainan dan sukan yang disertai manakala atlet yang berorientasikan ego kurang menikmati permainan dan sukan yang disertai. Mereka juga dikatakan akan keluar gelanggang atau padang dengan lebih awal.

Kajian terhadap orientasi matlamat dan keseronokan telah dikaji dalam pelbagai konteks. Contohnya orientasi matlamat dan motivasi oleh Anagnostou, Patsiaouras, Stell, \& Kokaridas (2013) dan penglibatan aktiviti fizikal dan keseronokan oleh Michael et.al (2016). Namun, berdasarkan kajian kajian terdahulu, hanya beberapa kajian yang telah dijalankan oleh Jaakkola et.al (2016) dan Schneider et.al (2017) untuk melihat perkaitan antara orientasi matlamat dan keseronokan. Hasil bagi kedua - dua kajian yang dilakukan terhadap atlet lelaki tersebut dapat dirumuskan bahawa orientasi matlamat tugasan dapat meningkatkan keseronokan pemain. Oleh itu, kajian ini dijalankan untuk mengenal pasti orientasi matlamat dan tahap keseronokan atlet di Malaysia khususnya atlet di peringkat universiti. Kajian ini menjangkakan bahawa pemain hoki UPSI berorientasikan tugasan akan lebih seronok dalam sukan hoki. Tujuan utama kajian ini ialah untuk mengkaji hubungan antara orientasi matlamat dan tahap keseronokan atlet hoki UPSI disamping melihat perbezaan orientasi matlamat dan tahap keseronokan atlet mengikut jantina.

\section{METODOLOGI}

\section{Peserta}

Kajian ini adalah berbentuk diskriptif. Responden kajian ini melibatkan 30 pemain hoki, lelaki $(n=17)$ dan wanita $(\mathrm{n}=13)$ yang berumur antara 18 tahun hingga 24 tahun. Responden kajian adalah terdiri daripada pemain-pemain hoki yang mewakili universiti dalam sukan hoki.

\section{Instrumen}

Soal selidik Task and Ego Orientation in Sport Questionnaire (TEOSQ) yang telah digubal oleh Duda \& Nicholls (1989) digunakan untuk melihat orientasi matlamat pemain hoki. Soal selidik ini mengandungi 13 item yang menggambarkan sama ada penglibatan pemain berdasarkan orientasi ego atau tugasan. Elemen ego terbahagi kepada 6 soalan, manakala elemen tugasan terbahagi kepada 7 soalan. Responden diminta memberikan persetujuan berdasarkan skala likert 5 markah $(1=$ sangat tidak setuju hingga $5=$ sangat setuju). Soal selidik ini telah dialih bahasa oleh Shahrudin (1998) dan mempunyai nilai kebolehpercayaan 0.80 .

Manakala, soal selidik Physical Activity Enjoyment Scale (PACES) yang telah dibangunkan oleh Kendzierski \& DeCarlo (1991) dialih bahasa ke bahasa melayu melalui proses back-translation. Soal selidik ini digunakan untuk melihat tahap keseronokan atlet hoki dalam aktiviti fizikal. Soal selidik ini mengandungi 18 item dan menggunakan skala likert 7-poin. Responden diminta memberikan persetujuan berdasarkan skala likert 7 markah, 7 item dinilai menggunakan skala $(1=$ sangat tidak setuju hingga $7=$ sangat setuju) manakala 11 item dinilai menggunakan skala $(1=$ sangat setuju hingga $7=$ sangat tidak setuju).

\section{Prosedur}

Kajian ini dijalankan menggunakan metodologi tinjauan iaitu mengukur perkaitan orientasi matlamat dan keseronokan atlet hoki UPSI menggunakan instrument soal selidik. Mereka juga diminta untuk menjawab soalan-soalan secara jujur dan tempoh masa yang mencukupi untuk menjawab kedua - dua soal selidik. Peserta diberikan soal selidik TEOSQ terlebih dahulu diikuti soal selidik PACES. Sebelum pengumpulan data dijalankan, jurulatih dan peserta kajian telah dimaklumkan tentang tujuan dan teknik menjawab soal 
selidik kajian ini. Soal selidik akan dikumpul sebaik sahaja responden menjawab kesemua pernyataan dalam soal selidik yang diberikan. Kajian ini telah mendapat persetujuan daripada jurulatih dan peserta sebelum memulakan kajian.

\section{Analisis Statistik}

Perisian statistik SPSS 23.0 digunakan bagi menganalisis data yang diperoleh. Berdasarkan objektif kajian, diskriptif statistik; skor min, sisihan piawai dan ujian-t sampel tidak bersandar dipilih untuk menganalisis perbezaan orientasi matlamat dan keseronokan atlet hoki lelaki dan perempuan. Manakala ujian korelasi Pearson pula digunakan dalam menganalisis perkaitan diantara orientasi matlamat dan tahap keseronokan atlet hoki UPSI. Penetapan nilai signifikan yang digunakan dalam kajian ini ialah $\mathrm{p}<0.05$.

\section{KEPUTUSAN}

Jadual 1 menunjukkan analisa ujian-t sampel tidak bersandar digunakan bagi membandingkan skor min orientasi matlamat antara atlet hoki lelaki dan atlet hoki perempuan. Ujian bagi orientasi tugasan menunjukkan nilai $\mathrm{t}(28)=0.44, \mathrm{p}=0.65>0.05$ adalah tidak signifikan. Keputusan ujian menunjukkan bahawa tidak terdapat perbezaan skor min orientasi tugasan yang signifikan diantara atlet hoki lelaki $(\mathrm{M}=$ $4.31, \mathrm{SD}=0.77)$, dengan atlet hoki perempuan $(\mathrm{M}=4.20, \mathrm{SD}=0.31)$. Manakala bagi ujian orientasi ego pula menunjukkan nilai t $(28)=2.14, \mathrm{p}=0.041<0.05$ adalah signifikan. Keputusan ujian menunjukkan bahawa terdapat perbezaan skor min orientasi ego yang signifikan diantara atlet hoki lelaki $(\mathrm{M}=2.75, \mathrm{SD}$ $=0.48)$, dengan atlet hoki perempuan $(\mathrm{M}=2.38, \mathrm{SD}=0.44)$. Atlet hoki lelaki didapati lebih berorientasikan ego berbanding wanita. Berdasarkan keputusan ujian tersebut, orientasi matlamat tugasan bagi kedua-dua jantina berada di peringkat tinggi berbanding orientasi matlamat; ego yang berada di peringkat sederhana. Ini menunjukkan atlet hoki lelaki dan perempuan UPSI lebih berorientasikan tugasan berbanding ego.

Jadual 1: Diskriptif Statistik dan Ujian-t Sampel Tidak Bersandar Orientasi Matlamat

\begin{tabular}{|c|c|c|c|c|c|c|c|c|}
\hline & \multirow[b]{2}{*}{ Jantina } & \multirow[b]{2}{*}{$N$} & \multirow[b]{2}{*}{ Skor Min } & \multirow[b]{2}{*}{$\begin{array}{l}\text { Sisihan } \\
\text { Piawai }\end{array}$} & \multirow[b]{2}{*}{$\begin{array}{l}\text { Indikator } \\
\text { Skor Min }\end{array}$} & \multicolumn{3}{|c|}{ t-test for Equality of Means } \\
\hline & & & & & & $T$ & $D f$ & $\begin{array}{l}\text { Sig. } \\
\text { tailed) }\end{array}$ \\
\hline \multirow[t]{2}{*}{ Tugasan } & Lelaki & 17 & 4.31 & .77 & Tinggi & .44 & 28 & .65 \\
\hline & Perempuan & 13 & 4.21 & .32 & Tinggi & .49 & 22.38 & .62 \\
\hline \multirow[t]{2}{*}{ Ego } & Lelaki & 17 & 2.75 & .49 & Sederhana & 2.14 & 28 & .04 \\
\hline & Perempuan & 13 & 2.38 & .44 & Sederhana & 2.17 & 27.07 & .03 \\
\hline
\end{tabular}

*Indikator skor min : <1.66 (rendah), 1.67-3.32 (sederhana), dan >3.33 (tinggi)

*Perbezaan signifikan: $p<0.05$

Jadual 2 menunjukkan analisa ujian-t sampel tidak bersandar digunakan bagi membandingkan skor min tahap keseronokan antara atlet hoki lelaki dan atlet hoki perempuan. Ujian bagi tahap keseronokan menunjukkan nilai $\mathrm{t}(28)=1.25, \mathrm{p}=0.22>0.05$ adalah tidak signifikan. Keputusan ujian menunjukkan bahawa tidak terdapat perbezaan skor min tahap keseronokan yang signifikan diantara atlet hoki lelaki (M $=3.74, \mathrm{SD}=0.54)$, dengan atlet hoki perempuan $(\mathrm{M}=3.52, \mathrm{SD}=0.39)$. Berdasarkan keputusan ujian tersebut, tahap keseronokan atlet hoki bagi kedua-dua jantina berada ditahap sederhana. 
Jadual 2: Diskriptif Statistik dan Ujian-t Sampel Tidak Bersandar Tahap Keseronokan

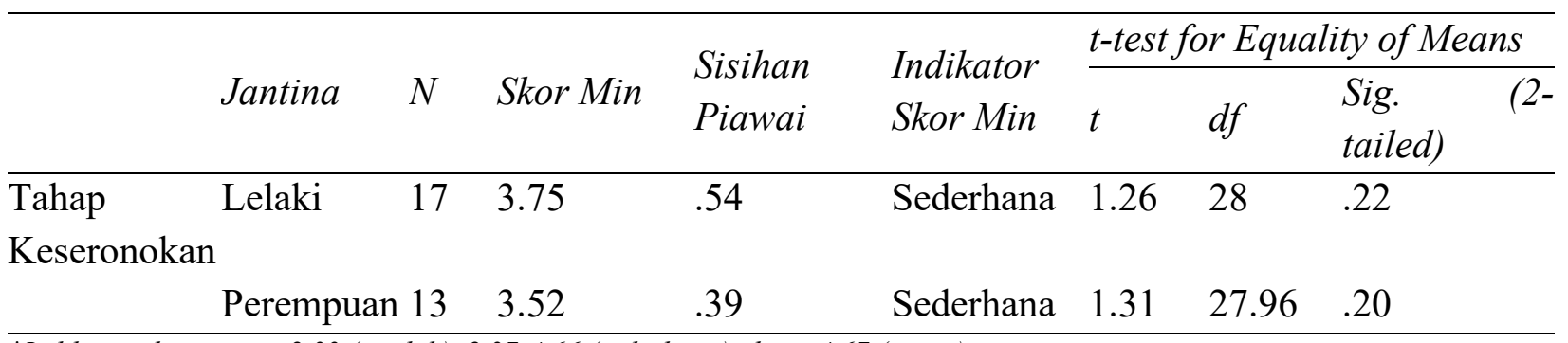

*Indikator skor min : <2.33 (rendah), 2.37-4.66 (sederhana), dan >4.67 (tinggi)

*perbezaan signifikan: $p<0.05$

Jadual 3 menunjukkan nilai pekali korelasi diantara skor min orientasi tugasan dengan skor min tahap keseronokan atlet hoki adalah positif dan rendah $(\mathrm{r}=0.026)$. Perkaitan antara kedua-dua pemboleh ubah tersebut adalah tidak signifikan $(r=0.026, n=30, p=0.89, p>0.05$. Ini bermakna, wujud perkaitan yang lemah antara pemboleh ubah orientasi tugasan dengan tahap keseronokan. Dapatan korelasi diantara orientasi ego dan tahap keseronokan pula menunjukkan nilai kolerasi yang kuat $(\mathrm{r}=0.56)$ dan perkaitan kedua-dua pemboleh ubah ini adalah signifikan $(\mathrm{r}=0.56, \mathrm{n}=30, \mathrm{p}=0.001, \mathrm{p}<0.05)$. Oleh itu, orientasi ego adalah berkaitan dengan tahap keseronokan atlet.

Jadual 3: Korelasi Pearson

\begin{tabular}{lll}
\hline & & Tahap Keseronokan \\
\hline Orientasi Tugasan & Korelasi Pearson & .026 \\
& Sig. (2-tailed) & .890 \\
\multirow{2}{*}{ Orientasi Ego } & $\mathrm{N}$ & 30 \\
& Korelasi Pearson & $.567^{* *}$ \\
& Sig. (2-tailed) & .001 \\
& $\mathrm{~N}$ & 30 \\
\hline
\end{tabular}

**. Korelasi signifikan pada aras 0.01 level (2-tailed).

\section{PERBINCANGAN}

Berdasarkan keputusan kajian menunjukkan bahawa tidak terdapat perbezaan skor min orientasi tugasan yang signifikan diantara atlet hoki lelaki dengan atlet perempuan. Namun, terdapat perbezaan skor min orientasi ego yang signifikan diantara atlet lelaki dengan atlet perempuan. Dapatan kajian tersebut mempunyai persamaan dengan dapatan kajian yang telah dijalankan oleh (Anagnostou et.al 2013; Gomez-Lopez, Granero-Gallegos, Baena-Extremera \& Abraldes, 2014; Saadan et.al, 2016) yang mana atlet lelaki mempunyai orientasi ego yang lebih tinggi berbanding atlet perempuan. Atlet lelaki didapati lebih bermotivasi untuk meneruskan penglibatan jika mereka berjaya mengalahkan pihak lawan berbanding dengan atlet perempuan yang fokus kepada matlamat untuk menguasai sesuatu kemahiran atau tugasan. Menurut Gomez-Lopez et.al (2014) dalam sukan bola tampar menunjukkan bahawa atlet perempuan lebih mengetahui tentang kepentingan melaksanakan latihan tetapi bagi atlet muda, mereka mempunyai perasaan serba salah kerana sering diperkenalkan oleh jurulatih dalam pasukan walaupun tanpa kerelaan, perlu menerima peraturan baru, rakan sepasukan baru, dan menggalas tangunggjawab yang besar. Orientasi matlamat tugasan bagi kedua-dua jantina berada di peringkat tinggi berbanding orientasi matlamat ego berada di peringkat sederhana. Ini menunjukkan bahawa atlet hoki lelaki dan perempuan UPSI lebih berorientasikan tugasan berbanding ego. Bersesuaian dengan pernyataan (Lameiras, et.al 2014) yang menyatakan bahawa matlamat atlet adalah berfokus kepada orientasi tugasan 
seperti meningkatkan prestasi berbanding ego iaitu berasa lebih baik daripada orang lain dalam sukan berkumpulan. Secara keseluruhannya, orientasi tugasan akan memberikan strategi yang efektif dalam kemahiran sukan, memperkuatkan usaha, dan secara tidak langsung akan berasa seronok dalam melaksanakan tugasan dalam sukan.

Tujuan kedua kajian ini dijalankan ialah bagi mengkaji tahap keseronokan atlet hoki lelaki dan perempuan. Hasil dapatan menunjukkan tidak terdapat perbezaan skor min yang signifikan diantara atlet hoki lelaki dan perempuan UPSI kerana atlet lelaki dan perempuan mempunyai tahap keseronokan yang sama iaitu sederhana. Namun, dapat dilihat berdasarkan skor min, atlet lelaki mempunyai tahap keseronokan yang lebih tinggi berbanding atlet perempuan. Perbezaan yang diperkatakan ini merupakan perbezaan yang tipis iaitu lelaki $(M=3.7451)$ manakala perempuan $(M=3.5214)$. Dapatan ini menyokong pernyataan Johnson et.al (2017) yang menyatakan bahawa atlet lelaki lebih cenderung menikmati keseronokan dalam sukan berbanding perempuan.

Perkaitan antara kedua-dua pemboleh ubah iaitu orientasi tugasan dan tahap keseronokan tersebut adalah signifikan $(r=0.026, n=30, p=0.89, p<0.05$. Manakala, orientasi ego dan tahap keseronokan menunjukkan perkaitan yang kuat dan signifikan $(\mathrm{r}=0.56, \mathrm{n}=30, \mathrm{p}=0.001, \mathrm{p}<0.05)$. Oleh itu, dapatan ini membuktikan bahawa aspek ego mempengaruhi tahap keseronokan atlet. Ini kerana aspek orientasi ego memberi kepuasan terhadap individu apabila mereka mempamerkan diri dan membandingkan prestasinya dengan orang lain. Dapatan ini bertentangan daripada dapatan kajian yang Schneider et.al (2017) menyatakan bahawa atlet yang berorientasikan ego kurang menikmati permainan dan sukan yang disertai. Oleh itu, hipotesis awal ditolak bahawa atlet yang berorientasikan tugasan akan lebih seronok dalam penglibatan dan permainan hoki. Namun, terdapat dapatan kajian yang menyokong bahawa atlet yang lebih berorientasikan ego mempunyai daya persaingan yang tinggi untuk bermain dan berlatih serta disifatkan sebagai individu yang tidak mudah menyerah kalah (Balish, Mclaren, Rainham \& Blanchard, 2014). Ini dapat dilihat menerusi kajian Deelen, Ettema \& Kamphuis (2018) terhadap pemain bola sepak dan tenis yang pernah bermain dalam pasukan pemilihan (tahap persaingan yang lebih tinggi) didapati kurang kecenderungan untuk menyerah kalah ketika sesi pemilihan dijalankan. Oleh itu, atlet yang mempunyai orientasi ego yang tinggi tidak mempunyai kesan negatif terhadap prestasinya (Vansteenkiste, Matos, Len, \& Soenens, 2007) dan penyertaan dalam sukan Ntoumanis (2001). Kesimpulannya, atlet yang berorientasikan ego mempunyai kelebihan dalam sukan dan ia juga diperlukan untuk seseorang atlet itu mencapai kejayaan dengan memiliki kedua - dua orientasi (tugasan dan ego).

\section{KESIMPULAN}

Hasil dapatan kajian ini dilihat tidak konsisten dengan dapatan kajian - kajian lampau. Oleh itu, kajian lanjutan perlu dilakukan untuk melihat konsistensi dapatan kajian. Selain itu, kajian ini boleh dijadikan rujukan kepada pihak yang terlibat secara langsung dengan atlet seperti jurulatih dan ahli psikologi. Aspek keseronokan, orientasi tugasan dan ego dapat dijadikan sebagai garis panduan dalam merangka latihan dan strategi sesebuah pasukan. Kejayaan atlet bukan dilihat dari satu sudut sahaja, tetapi kedua - dua orientasi tersebut diperlukan untuk melengkapi aspek keseronokan. Atlet hoki perlu diterapkan latihan kemahiran psikologi yang lebih spesifik dan memberi kesan kepada peningkatan orientasi matlamat kerana ia mempengaruhi tahap keseronokan atlet.

\section{RUJUKAN}

Anagnostou. G, Patsiaouras. A, Stell. D \& Kokaridas. D (2013). Goal orientation and participation motivation in tennis young players. Journal of Physical Education and Sport. 13(3), 464-470

Balish, S. M., McLaren, C., Rainham, D., \& Blanchard, C. (2014). Correlates of youth sport attrition: A review and future directions. Psychology of Sport and Exercise, 15(4), 429-439.

Clark, A. V. (2005).-Psychology of moods. Nova Publishers.

Deelen, I., Ettema, D., \& Kamphuis, C. B. (2018). Sports participation in sport clubs, gyms or public spaces: How users of different sports settings differ in their motivations, goals, and sports frequency. PloS One, 13(10), $\mathrm{e} 0205198$. 
Duda, J. L., \& Nicholls, J. G. (1989). The task and ego orientation in sport questionnaire: Psychometric properties. Unpublished manuscript, 1-13.

Gomez-Lopez. M, Granero-Gallegos. A, Baena-Extremera. A \& Abraldes, J.A (2014). Goal orientation effects on elite handball players' motivation and motivational climate, Procedia Social and Behavioral Sciences, 132, 434 440

Jaakkola, T., Ntoumanis, N., Liukkonen, J. (2016). Motivational climate, goal orientation, perceived sport ability, and enjoyment within Finnish junior ice hockey players.-Scandinavian, Journal of Medicine Science in Sports, 26(1), 109115.

Johnson, C. E., Erwin, H. E., Kipp, L., Beighle, A. (2017). Student perceived motivational climate, enjoyment, and physical activity in middle school physical education. Journal of Teaching in Physical Education, 36(4), 398408.

Kendzierski, D., \& DeCarlo, K. J. (1991). Physical activity enjoyment scale: Two validation studies. Journal of Sport and Exercise Psychology, 13(1), 50-64.

Lameiras, J., Almeida, P. L., \& Garcia-Mas, A. (2014). Relationships between cooperation and goal orientation among male professional and semi-professional team athletes. Perceptual and Motor Skills, 119(3), 851-860.

Lochbaum, M., Kallinen, V., \& Konttinen, N. (2017). Task and ego goal orientations across the youth sports experience. Studia Sportiva, 11(2), 99-105.

Michael, S. L., Coffield, E., Lee, S. M., Fulton, J. E. (2016). Variety, enjoyment, and physical activity participation among high school students. Journal of Physical Activity Health, 13(2), 223230.

Mohd Sofian Omar Fauzee \& Abdul Razak Ismail (2005). Goal orientation and beliefs about causes of sport success among Malaysia athletes. Journal for Physical, Health Education, Recreation and Dance. 11(2), 112-120.

Ntoumanis, N. (2001). Empirical links between achievement goal theory and self-determination theory in sport. Journal of Sports Sciences, 19(6), 397-409.

Saadan. R, Hooi, L. B, Ali, H. M, \& Jano Z. (2016). The relationship between competitive anxiety and goal orientation among junior hockey athletes. Journal of Sport and Physical Education, 3(1).33-37

Scanlan, T. K., Carpenter, P. J., Lobel, M., Simons, J. P. (1993). Sources of enjoyment for youth sport athletes.Pediatric Exercise Science, 5(3), 275-285.

Schneider, R., Harrington, M., \& Tobar, D. (2017). Goal orientation and how a task or ego mentality can affect the enjoyment for college hockey players. College Student Journal, 51(1), 57-62.

Sorate, B.A \& Khan. A (2016). The task and ego orientation of different games players of Jimma University. Turkish Journal of Sport and Exercise, 18(3), 8-11.

Vansteenkiste, M., Matos, L., Lens, W., \& Soenens, B. (2007). Understanding the impact of intrinsic versus extrinsic goal framing on exercise performance: The conflicting role of task and ego involvement. Psychology of Sport and Exercise, 8(5), 771-794.

Weiss, M. R., Ferrer-Caja, E., \& Horn, T. S. (2002). Advances in sport psychology. Moral development in sport and physical activity: theory, research, and intervention. Champaign, IL. Human Kinetics.

Nabilah Yaakub

Fakulti Sains Sukan dan Kejurulatihan, Universiti Pendidikan Sultan Idris, Malaysia

Email: nabilahyaakub14@gmail.com 